\title{
Bleeding breast mass in a prepubertal child: Benign or malignant? An unusual case of bleeding juvenile fibroadenoma
}

\author{
Johann Paulo S. Guzman, Leandro L. Resurreccion, Marcus Lester R. Suntay, Alvin B. Caballes \\ Philippine Children's Medical Center, Quezon City, Philippines
}

Received: April 12, 2017

Accepted: May 23, 2017

Online Published: August 18, 2017

DOI: $10.5430 /$ css.v3n3p19

URL: https://doi.org/10.5430/css.v3n3p19

\begin{abstract}
Malignancy is often suspected in a rapidly growing bleeding breast mass. In the pediatric population, where the majority of tumors are benign, these masses can have clinical presentations that mimic malignant tumors. This is a case of an eleven year old prepubertal female with a huge bleeding breast mass who underwent mastectomy with final histopathology showing giant fibroadenoma. The patient and her relatives were reassured of the benign nature of her disease. We report an uncommon benign condition in children which can be mistaken for a malignant condition often seen in adults. We also present a review on different breast conditions in the pediatric age group and its management.
\end{abstract}

Key Words: Bleeding fibroadenoma, Breast mass, Prepubertal child

\section{INTRODUCTION}

It has been suggested that bleeding is a warning sign of malignancy in breast masses especially if it is accompanied by rapid growth of the mass. Malignant tumors stimulate growth of blood vessels by neovascularization, and the onset of angiogenesis is needed for rapid expansion of a tumor population. ${ }^{[1]}$ Angiogenesis however, may not necessarily denote an invasive tumor or malignancy. ${ }^{[2]}$ This is supported by Doppler Color Sonography studies on different breast lesions which show no significant differences in blood flow patterns between benign and malignant breast mass. ${ }^{[3]}$

Though breast masses are uncommon in the pediatric population, the detection of an abnormally fast growing breast mass accompanied by bleeding is often alarming to patients and caregivers. Most breast conditions arising in the pediatric age group are benign, with fibroadenomas being the most common breast mass in the adolescent. ${ }^{[4]}$ Most commonly suggested risk factors for malignancy include ulceration, skin changes, rapidly growing tumors, and bleeding. Juvenile or giant fibroadenomas account for $0.5 \%-2 \%$ of all cases of fibroadenomas. characterized by their large size (greater than $5 \mathrm{~cm}$ ), multicentricity and may sometimes mimic a cystosarcoma phyllodes. ${ }^{[5,6]}$ Bleeding is a rare presentation in these kinds of tumors, having been reported only anecdotally in literature. ${ }^{[4,7,8]}$

\section{Case reports}

An 11-year-old prepubertal female presented with a one year history of a progressively growing left breast mass. This was initially noticed by the patient when the size of the lesion was about one by two centimetres and located at the upper

\footnotetext{
*Correspondence: Johann Paulo S. Guzman, MD; Email: yooohannn@yahoo.com; Address: Philippine Children’s Medical Center, Quezon City, Philippines.
}

Published by Sciedu Press 
outer quadrant. Within six months, the mass was perceived to have grown to about ten by eleven centimeters size. By the tenth month or two months prior to consult at our institution, a small ulceration became evident at the left nipple.

Initial ultrasound showed that the left breast was converted into a heterogenous large solid mass (eleven by eleven by eight centimeters), with areas of necrosis within and no axillary lymph node enlargements. Normal sonogram of the right breast was reported. The patient had a core needle biopsy done outside of our institution, which was interpreted as juvenile papillomatosis (Swiss chesse disease) due to the presence of papillary epithelial hyperplasia within small ducts and lobules. The patient was referred to our institution with the mass already measuring twenty by twenty centimeters in size with bleeding near the nipple areola complex (see Figure 1).

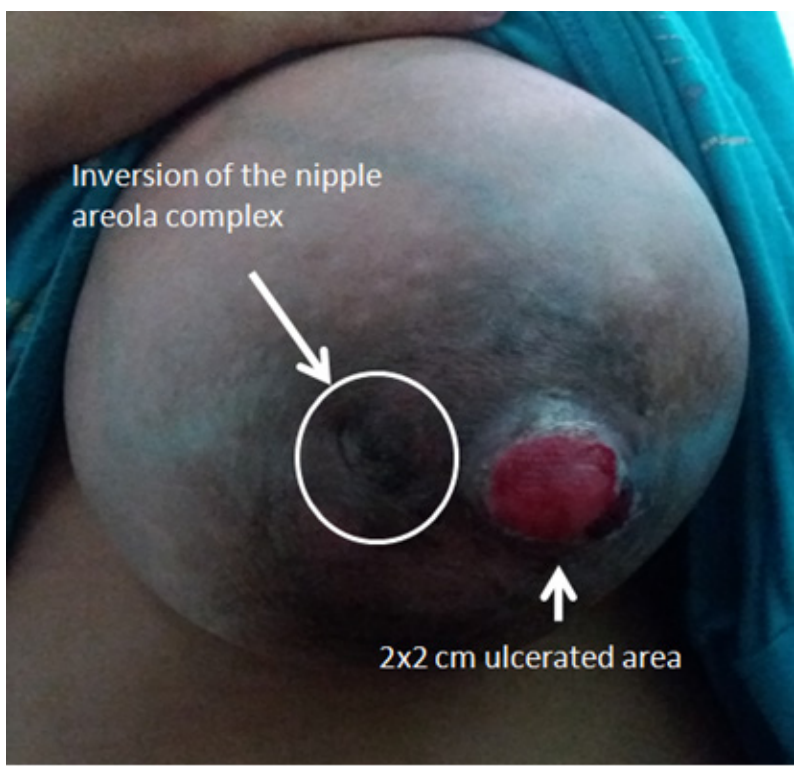

Figure 1. Large left breast mass with nipple inversion and adjacent $2 \mathrm{~cm} \times 2 \mathrm{~cm}$ ulcerated area

There was no history of trauma, lactorrhea, burning sensation, fever, fatigue or weight loss. The patient's parents denied familial history of breast diseases or history of previous radiation to the breast. On physical examination her weight was $37 \mathrm{~kg}$. There was no cervical or axillary lymph node enlargement. The left breast mass was firm, round, movable from the chest wall with tense skin and engorged superficial vessels. The nipple was inverted with a friable ulceration lateral to it (see Figure 1). The right breast was clinically Tanner Stage III with elevation of the breast and papilla and no separation of contours (see Figure 2).

Although a pre-operative biopsy was done showing juvenile papillomatosis, a malignant pathology was clinically suspected in this patient because of the fast growing and bleeding nature of the tumor. To assess resectability, a chest CT scan was done which showed a non-calcified, heterogenously enhancing left breast mass with smooth borders non invading the bony thorax and no pulmonary nodules. Mastectomy, with plans of delayed breast reconstruction was advised for the patient because there was no more clinically identifiable normal breast tissue.

A simple mastectomy was subsequently done, with no lymph node dissection. A drain was inserted and output was monitored post-operatively. The massively enlarged breast measured twenty by twenty centimeters in size, weighed two kilograms and on cut section showed a tan brown colored fleshy mass (see Figures 3 and 4).

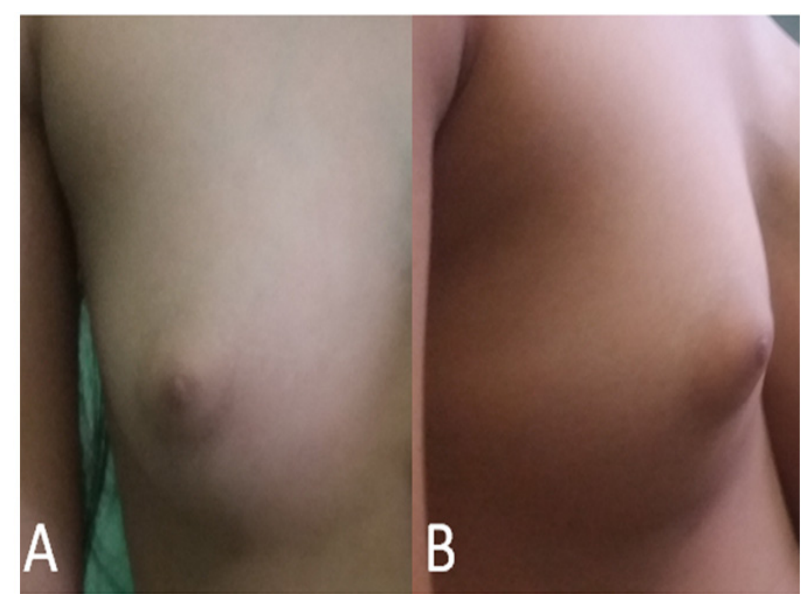

Figure 2. Right breast of the patient clinically Tanner Stage III: (A) anteroposterior view, (B) lateral view

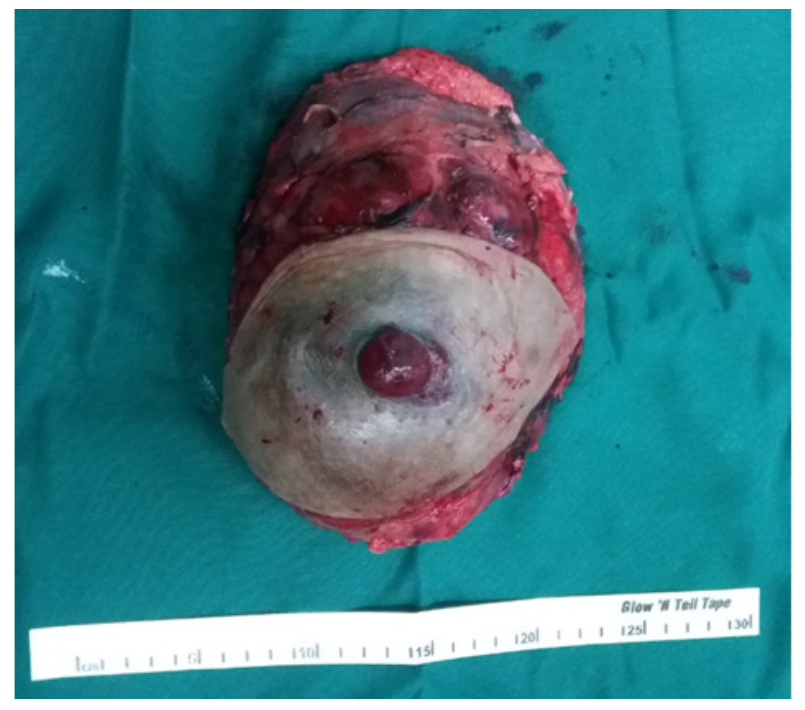

Figure 3. Mastectomy specimen 


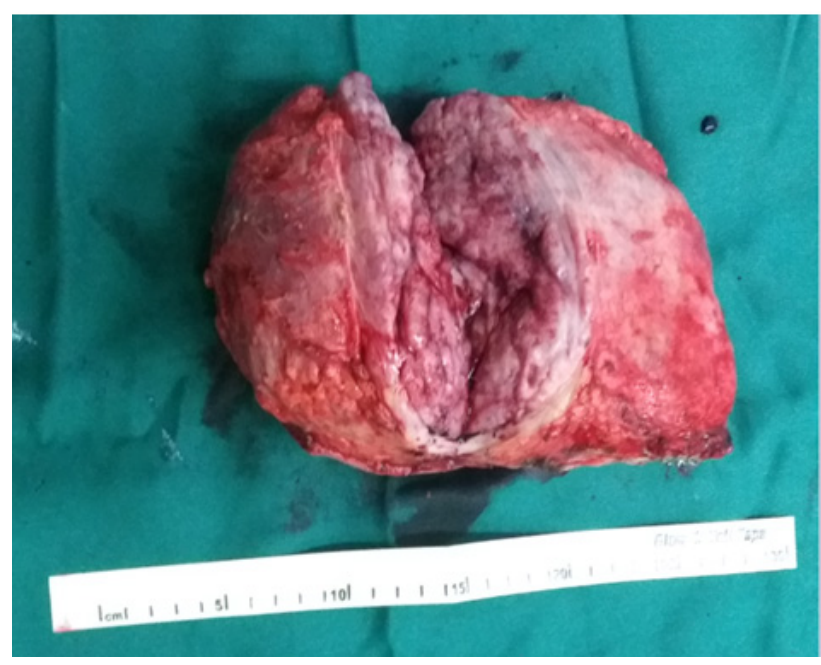

Figure 4. Cut section of the specimen

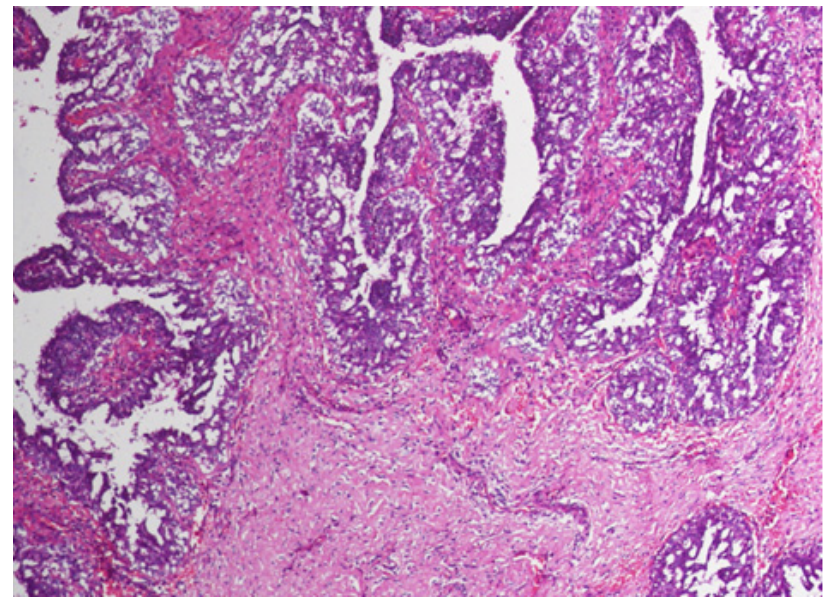

Figure 5. Microsopic sections showing increased stromal growth and cellularity

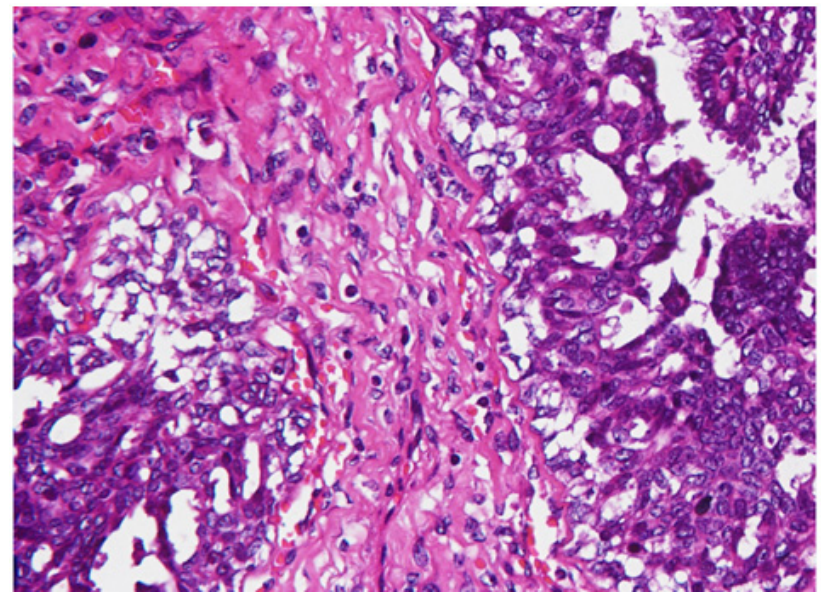

Figure 6. Sections show no atypical or malignant cells seen

Histopathologic examination showed benign breast parenchyma with increased stromal growth and cellular-

Published by Sciedu Press ity. Epitthelial hyperplasia in micropapillary and cribriform patterns were evident. No atypical and malignant cells were seen (see Figures 5 and 6).

The patient had an unremarkable post-operative course, with no wound complications and the drain was removed days after surgery. She was discharged with an advice for breast reconstruction.

\section{DisCUSSION}

Most pediatric breast masses in adolescents are benign. $\mathrm{Re}$ gardless of histologic type, $10 \%-40 \%$ of clinically detected masses in adolescents resolve spontaneously. ${ }^{[9]}$ In a 20year pathologic review on prepubertal benign breast masses by Inder et al., ${ }^{[10]}$ thirty-seven cases of benign breast cases were collected. Fibroadenoma was the most common in 22 $(59.5 \%)$ cases, juvenile fibroadenoma in 9 (24.2\%) cases, virginal hypertrophy in $3(8.1 \%)$ cases, cystosarcoma phylloides, duct papilloma and tuberculosis of the breast in one $(2.7 \%)$ case were seen.

Other benign breast disorders reported in the literature are premature thelarche which may be secondary to precocious puberty, virginal hyperthrophy, hamartoma and abscess formation. Benign premature thelarche is defined as an isolated breast development in females between ages 6 months and 9 years. If thelarche is isolated, treatment is reassurance because they usually regress within one to two years. If there is bilateral premature onset of thelarche, other signs of precocious puberty should be sought as they may be subtle presentations of ovarian or adrenal tumors. ${ }^{[6]}$

Virginal hypertrophy, another benign breast mass, commonly presents with bilateral diffuse involvement rather than a unilateral asymmetric involvement. It presents in the prepubertal period with bilateral involvement sometimes as rapidly growing tumors, with histological similarities to a giant fibroadenoma. ${ }^{[11]}$ Breast hamartomas are rare benign tumours that lead to unilateral breast enlargement without a palpable localized mass lesion, in comparison to a fibroadenoma. These often present in the post-pubertal age group. Histologically, a hamartoma consists of varying amounts of adipose, gland, and smooth muscle tissue. ${ }^{[12]}$ Breast infections occur in the prepubertal population but often present with signs of inflammation, cellulitis and abscess formation.

Tuberculosis which is endemic in the Philippines can theoretically present in the prepubertal breast. However, no such reports are made at the present time. The breast is resistant to tuberculous infection by blood stream, even in debilitated patients of tuberculosis. Breast tuberculosis is usually an extension from contiguous structures such as infected rib, costochondral cartilage, sternum, shoulder joint and even 
through the chest wall, with other systemic signs of chronic infections. ${ }^{[13]}$

Giant fibroadenoma is defined as breast mass of more than $5 \mathrm{~cm}$ or a weight greater than $500 \mathrm{~g} .{ }^{[14]}$ Many characteristics of giant juvenile fibroadenoma are typically considered indicators of malignancy. The mass can compress adjacent tissue, distort lobular architecture and create peau de orange , nipple inversion, skin dimpling or dilatation of superficial veins. Therefore, a pathologic diagnosis is required to rule out malignant disease in these patients. ${ }^{[6]}$ Hormonal influences are thought to be contributing factors. Excessive estrogen stimulation and/or receptor sensitivity or reduced levels of estrogen anatagonist have been implicated. ${ }^{[15]}$ These tumors have a tendency for prolific growth sometimes outstripping their blood supply leading to necrosis and eventually bleeding. ${ }^{[14]}$ In relation to our patient, this could explain the presentation of a bleeding breast mass suggestive of a malignancy. Nonetheless, in pediatric patients in whom benign lesions are more common, it is still prudent to consider the diagnosis of malignancy.

Although a pre-operative biopsy is not a standard part of the algorithm for a unilateral pediatric breast tumor work-up because majority of these are benign, it has a role in cases where there is a need to rule out suspicious malignancy. As in this case, a pre-operative biopsy was done to this patient showing juvenile papillomatosis. However, due to the clinical background in this patient, a phylloides cystosarcoma was considered due to possible unsampled areas that may have harbored malignancy.

In a study by Komenaka et al., ${ }^{[16]}$ core needle biopsy is considered a useful diagnostic tool in differentiating a malignant entity such as phyllodes cystosarcoma from fibroadenoma with a $93 \%$ negative predictive value and a positive predictive value of $83 \%$. This points that a core needle biopsy is a rational first step in the algorithm when a physician encounters a breast mass in the pediatric population, and should be part of the pre-operative work-up in patients for extensive surgery.

There are some who suggest alternative therapy other than surgery, implying the potential role for hormonal therapy. Theories of hormonal stimulation are implicated in the pathology of benign breast lesions. Hence, hormonal therapy theoretically is a logical approach for patients where surgery is not an option, especially in severe medical conditions preventing surgery. However, tamoxifen has yet to be proven in this setting. Unfortunately, tamoxifen is not a benign drug considering its side effects especially in the younger population. ${ }^{[17]}$ This can be active area for research identifying the role for anti-estrogen therapy in breast diseases in the pediatric age group.

In other rare cases in which pursuing a diagnosis of malignancy by biopsy is equivocal, blood markers for vasculogenesis may have a role. In a study by Sussman in 2003 among women undergoing breast surgery for different malignancies, a clear increase in peripheral Tie-2 with a smaller increase in ACI33 and VEGFR-2 expression was seen in these patients. ${ }^{[18]}$ These markers may be of use among pediatric patients, but their actual value remains to be validated.

We are presented with a rare case of a bleeding, rapidly proliferating giant fiboradenoma of the breast in a prepubertal child. Mastectomy was done with plans of delayed breast reconstruction at an appropriate age. It is important to discuss carefully the benign nature of fibroadenoma as well as the occurrence of these lesions on the contralateral breast.

\section{CONFLICTS OF INTEREST Disclosure}

The authors declare they have no conflict of interest.

\section{REFERENCES}

[1] Eberhard A, Kahlert S, Goede V, et al. Heterogeneity of angiogenesis and blood vessel maturation in human tumors: implications for antiangiogenic tumor therapies. Cancer Res. 2000; 60(5): 1388-1393. PMid: 10728704.

[2] Raica M, Cimpean AM, Ribatti D. Angiogenesis in pre-malignant conditions. Eur J Cancer. 2009; 45(11): 1924-1934. PMid: 19406633. https://doi.org/10.1016/j.ejca.2009.04.007

[3] McNicholas MM, Mercer PM, Miller JC, et al. Color Doppler sonography in the evaluation of palpable breast masses. AJR Am J Roentgenol. 1993; 161(4): 765-771. PMid: 8372754. https: //doi.org/10.2214/ajr.161.4.8372754

[4] Arowolo OA, Akinkuolie AA, Adisa AO, et al. Giant fibroadenoma presenting like fungating breast cancer in a Nigerian teenager. Afri
Health Sci. 2013; 13(1): 162-165. https://doi.org/10.4314/ ahs.v13i1.23

[5] Baxi M, Agarwal A, Mishra A, et al. Multiple bilateral giant juvenile fibroadenomas of breast. Eur J Surg. 2000; 166(10): 828-830. PMid: 11071174. https://doi.org/10.1080/110241500447515

[6] Arca MJ, Caniano DA. Breast disorders in the adolescent patient. Adolesc Med Clin. 2004; 15(3): 473-485. https://doi.org/10 $.1016 / j$.admecli.2004.06.003

[7] Liu H, Yeh ML, Lin KJ, et al. Bloody nipple discharge in an adolescent girl: unusual presentation of juvenile fibroadenoma. Pediatr Neonatol. 2010; 51(3): 190-192. https://doi.org/10.1016/S1 875-9572(10)60036-8

[8] Song BS, Kim EK, Seol H, et al. Giant juvenile fibroadenoma of the breast: a case report and brief literature review. Ann Pe- 
diatr Endocrinol Metab. 2014; 19(1): 45-48. PMid: 24926464. https://doi.org/10.6065/apem.2014.19.1.45

[9] Vade A, Lafita VS, Ward KA, et al. Role of breast sonography in imaging of adolescents with palpable solid breast masses. AJR Am J Roentgenol. 2008; 191(3): 659-663. PMid: 18716091. https: //doi.org/10.2214/AJR.07.3390

[10] Inder M, Vaishnav K, Mathur DR. Benign breast lesions in prepubertal female children-a study of 20 years. J Indian Med Assoc. 2001; 99(11): 619-620. PMid: 12022201.

[11] Merdan I. Giant fibroadenoma: case report and review of the literature. Bas J Surg. 2006; 12: 16.

[12] Murat A, Ozdemir H, Yildirim H, et al. Hamartoma of the breast. Australas Radiol. 2007; 51(1): B37-B39. PMid: 17875153. https : //doi.org/10.1111/j.1440-1673.2007.01818.x

[13] Tewari M, Shukla HS. Breast tuberculosis: diagnosis, clinical features \& management. Indian J Med Res. 2005; 122(2): 103. PMid: 16177466.
[14] Kaneda HJ, Mack J, Kasales CJ, et al. Pediatric and adolescent breast masses: a review of pathophysiology, imaging, diagnosis, and treatment. AJR Am J Roentgenol. 2013; 200(2): W204-W212. PMid: 23345385. https://doi.org/10.2214/AJR.12.9560

[15] Nikumbh DB, Desai SR, Madan PS, et al. Bilateral giant juvenile fibroadenomas of breasts: a case report. Patholog Res Int. 2011. https ://doi.org/10.4061/2011/482046

[16] Komenaka IK, El-Tamer M, Pile-Spellman E, et al. Core needle biopsy as a diagnostic tool to differentiate phyllodes tumor from fibroadenoma. AMA Arch Surg. 2003; 138(9): 987-990. PMid: 12963656. https://doi.org/10.1001/archsurg.138.9.987

[17] Ewies T, Abbas A, Amr S, et al. Unilateral virginal breast hypertrophy in an 11-year-old girl. Breast J. 2013; 19(2): 202-204. PMid: 23406212. https://doi.org/10.1111/tbj. 12084

[18] Sussman LK, Upalakalin JN, Roberts MJ, et al. Blood markers for vasculogenesis increase with tumor progression in patients with breast carcinoma. Cancer Biol Ther. 2003; 2(3): 255-256. PMid: 12878859. https://doi.org/10.4161/cbt.2.3.363 